\title{
Antifungal Activity of Jasminum sambac against Malassezia sp. and Non-Malassezia sp. Isolated from Human Skin Samples
}

\author{
Jacinta Santhanam, Farhana Nadiah Abd Ghani, and Dayang Fredalina Basri \\ School of Diagnostic \& Applied Health Sciences, Faculty of Health Sciences, Universiti Kebangsaan Malaysia, \\ Jalan Raja Muda Abdul Aziz, 50300 Kuala Lumpur, Malaysia \\ Correspondence should be addressed to Dayang Fredalina Basri; dayang@ukm.edu.my
}

Received 31 July 2014; Revised 20 October 2014; Accepted 21 October 2014; Published 10 November 2014

Academic Editor: Simona Nardoni

Copyright (C) 2014 Jacinta Santhanam et al. This is an open access article distributed under the Creative Commons Attribution License, which permits unrestricted use, distribution, and reproduction in any medium, provided the original work is properly cited.

\begin{abstract}
Malassezia sp. causes skin diseases such as pityriasis versicolor, folliculitis, and atopic dermatitis. The present study aims to evaluate the antifungal activity of J. sambac or Arabian jasmine, a flowering plant abundant in the Southeast Asia against Malassezia sp. using disc diffusion and broth microdilution method. The methanol extract and essential oil from the flowers and leaves of $J$. sambac were, respectively, prepared using solvent extraction and hydrodistillation process. Skin samples from individuals with dandruff were cultured on Sabouraud dextrose agar overlaid with olive oil. The fungi that grew were observed microscopically, tested with Tween assimilation test, and cultured on CHROMagar (the chromogenic media pioneer) to identify Malassezia sp. Out of 5 skin samples, only 2 Malassezia sp. isolates were identified based on morphology and their ability to assimilate Tween. The inhibition zones of methanol extract of flowers and leaves of J. sambac and essential oil of flowers showed potential for antifungal activity with inhibition zones of $11.10 \pm 1.92,12.90 \pm 1.68$, and $13.06 \pm 0.26 \mathrm{~mm}$, respectively, and minimum inhibitory concentration (MIC) values of $80 \mathrm{mg} / \mathrm{mL}$ to $160 \mathrm{mg} / \mathrm{mL}$ and $50 \%$, respectively. In conclusion, J. sambac may be used as an alternative treatment against Malassezia-associated skin infections.
\end{abstract}

\section{Introduction}

Malassezia sp. is a type of glabrous fungus which causes infections of superficial layer of the skin. Malassezia species are normal flora found on the skin of 7 billion humans but they can be pathogenic causing the common skin disorder which includes pityriasis versicolor, folliculitis, and atopic dermatitis in humans [1]. In immunocompromised hosts, Malassezia can also cause systemic infections. Malassezia are lipophilic or lipid-dependent fungi requiring long chain fatty acids, essential for the growth of most Malassezia species, and are being supplied from the human skin lipids [2]. This lipid requiring property causes the highest density of Malassezia in the sebaceous areas such as the scalp, face, and upper trunk and the lowest density on the hands. Being a lipophilic yeast, therefore in vitro growth must be stimulated by natural oils or other fatty substances. The most common method used is to overlay Sabouraud dextrose agar with olive oil [3]. Reproduction of Malassezia sp. is by budding from a broad base present on the same cell pole (monopolar budding) [4]. Prolonged use of topical antifungals such as Itraconazole, Fluconazole, and Terbinafine to treat infections caused by Malassezia sp. has its drawbacks by causing side effects such as burning, stinging, or redness when applied to the skin. The main problem with oral antifungals is nausea and dizziness on continuous use [5]. Other drawbacks of commercial antifungals, whether topical or oral, are their adverse drug interaction with other medications and high cost in pharmacies [6].

In an effort to find an alternative from a more natural and safer source, it is very applicable to utilize the use of natural products. Recent study [7] on Jasminum sambac, a flowering plant abundant locally in Southeast Asia and traditionally used as remedies for skin problems such as acne, whitehead, and blackhead, has proven successful. This Arabian jasmine plant is distinctive for its flower's white petals which emit a fragrance odour and bloom throughout the year. The leaves of $J$ s sambac contain the secoiridoid glycosides, jasminin, quercitrin, and rutin [8]. The preliminary phytochemical study of the antimicrobial activity of ethanolic callus extracts 
of jasmine focused on two species of Jasminum, J. grandiflorum and J. sambac, showed that the plants can be used as medicine for skin disorders [9]. As J. sambac possesses antibacterial property, it can be used to treat acne and skin infections. Essential oil and extracts of J. sambac have been shown to exhibit antibacterial and antifungal properties [10]. Jasmine oil has been proven to reduce skin inflammation, tones the skin by repairing skin cells by encouraging cell growth, and increases skin elasticity [11].

Jasminum sambac has also been known to inhibit the growth of Alternaria sp. and dermatophytes[12]. The callous extracts of J. sambac were also reported to display antimicrobial activity against Staphylococcus albus, Proteus mirabilis, Salmonella typhi [13], and Propionibacterium acnes [14]. The use of $J$. sambac extract can be a potential additive in skin and hair products to prevent Malassezia sp. infection altogether [15]. The present study was therefore undertaken to confirm the effectiveness of methanol extract and essential oil from the leaves and flowers from J. sambac against Malassezia sp. isolated from the skin samples of individuals with dandruff.

\section{Materials and Methods}

2.1. Plant Materials. Fresh flowers and leaves of Jasminum sambac were purchased from a nursery located in Sungai Buloh, Selangor, Malaysia. Prior to analysis, the flowers and leaves were taken out of the freezer, thawed at room temperature, and then washed thoroughly under running tap water. The leaves and the flowers were then spread on the tray and allowed to dry at room temperature for several days. The dried flowers and leaves were grinded into powder using an electrical blender. Another batch of the flowers was left fresh for hydrodistillation process to obtain the essential oil.

2.2. Extraction of Plant. Two methods [16], namely, hydrodistillation and methanol extraction, were employed to produce essential oil and the crude methanol extract, respectively. In the preparation of essential oil, about $100 \mathrm{~g}$ of powdered leaves and $100 \mathrm{~g}$ of fresh flowers were added to a $500 \mathrm{~mL}$ round-bottom flask and filled half full with distilled water. The $500 \mathrm{~mL}$ distilling flask was rested on the heating mantel and was heated slowly while adding water sparingly from the separatory funnel to prevent the plant from drying out and burning. The distillation was stopped when the distillate reached $100 \mathrm{~mL}$. The distillate was extracted three times with $15 \mathrm{~mL}$ aliquot of dichloromethane. The combined dichloromethane layers were then extracted three times with $15 \mathrm{~mL}$ aliquot of saturated $\mathrm{NaCl}$. Magnesium sulphate $\left(\mathrm{MgSO}_{4}\right)$ was used as a drying agent to dry the organic layer. The filtrates were collected and left to evaporate in a beaker on a hot plate [17].

The crude extract was prepared from the dried powder of the leaves and flowers using methanol as the extraction solvent. In the ratio of $1: 5,100 \mathrm{~g}$ of the powdered J. sambac leaves and flowers was soaked in $500 \mathrm{~mL}$ methanol, respectively. The mixture was then subjected to agitation using magnetic stirrer for 24 hours at room temperature. The mixture was then filtered using the Whatman filter paper No. 1 whereby the filtrate obtained was collected. The process was repeated using the remaining residue with $250 \mathrm{~mL}$ methanol. Both filtrates were then mixed and concentrated under reduced pressure using a rotary evaporator. The extracts obtained were finally pounded to dryness under the fume hood in order to produce a crude methanol extract [18].

The essential oil and methanol extract were dissolved with $10 \%$ DMSO whereas the aqueous extract was dissolved in sterile distilled water to final concentration of $100 \%, 75 \%, 50 \%$, and $25 \%$ for essential oil and $10 \mathrm{mg} / \mathrm{mL}$, $20 \mathrm{mg} / \mathrm{mL}, 40 \mathrm{mg} / \mathrm{mL}, 60 \mathrm{mg} / \mathrm{mL}, 80 \mathrm{mg} / \mathrm{mL}, 160 \mathrm{mg} / \mathrm{mL}$, and $320 \mathrm{mg} / \mathrm{mL}$ for methanol extract. All the extracts were sterilized by passing through a $0.45 \mu \mathrm{m}$ pore membrane filter.

2.3. Preparation of Microorganism Strain. The skin samples were collected from the subjects under the approval of the Faculty Research Committee Code NN-2014-027. Using a sterile scalpel blade, the samples were placed in sterilized plastic bags for storage and transport to the laboratory. The fungal strains isolated from skin samples were mounted in $10 \% \mathrm{KOH}$, glycerol, Parker ink solution, and lactophenol cotton blue to identify the samples. It was also tested with $10 \% \mathrm{H}_{2} \mathrm{O}_{2}$ to investigate the presence of catalase which is an indicator of Malassezia sp. It was then inoculated on Sabouraud dextrose agar (SDA) plates overlaid with $1 \mathrm{~mL}$ olive oil as a source of lipid to which penicillin and streptomycin combination (PenStrep) was added to inhibit bacterial growth. The plates were incubated for 48 hours at $32^{\circ} \mathrm{C}$ after which the colonies were examined and studied. The colony was identified as Malassezia sp. after undergoing macroscopic colony test on SDA, microscopic observation by Gram staining, and Tween assimilation test [19].

2.4. Inoculum Preparation. The inoculum preparation of yeast suspension was standardized using a spectrophotometer. The optical density of the yeast suspension was adjusted to turbidity at absorbance (A) reading within the range of 0.08 at $625 \mathrm{~nm}$ which corresponded to $10^{8} \mathrm{CFU} / \mathrm{mL}$ whereas for the filamentous fungi, the same inoculum size was equivalent to absorbance (A) reading adjusted within the range of 0.09 to 0.13 at $530 \mathrm{~nm}$. Tween 80 was added as wetting agent to facilitate the preparation of inoculum [20].

2.5. Screening of Antimicrobial Activity. The extracts from the flowers and leaves of J. sambac were subjected to antifungal screening by agar disc diffusion method [21]. SDA plates which were overlaid with $1 \mathrm{~mL}$ of olive oil were inoculated with the test isolate by spreading the standardized inoculum on the surface of the agar plate with sterile swab. Holes of diameter $5 \mathrm{~mm}$ were punched onto the sterile filter paper and soaked with $20 \mu \mathrm{L}$ of each of the extract solutions at $25 \mathrm{mg} / \mathrm{mL}, 50 \mathrm{mg} / \mathrm{mL}, 75 \mathrm{mg} / \mathrm{mL}$, and $100 \mathrm{mg} / \mathrm{mL}$. Fluconazole disc $(40 \mathrm{mg} / \mathrm{mL})$ served as positive control whereas the disc containing $10 \%$ DMSO alone was used as a negative control for antifungal assay. The discs were dried for 8 hours and placed onto the agar plates. All the plates were incubated at $32^{\circ} \mathrm{C}$ for 48 hours in moist condition because this is the optimum growth temperature for all the fungi tested. 
The antimicrobial activity was assessed by measuring the diameter of the zone of inhibition in $\mathrm{mm}$ from observation of the clear zones formed surrounding each disc. The bioassay was performed in triplicate in order to calculate the mean value.

\subsection{Determination of Minimum Inhibitory Concentration.} The methanol extract from the flowers and leaves of $J$. sambac was subjected to antifungal sensitivity testing by broth microdilution method [22]. The 96-microtiter well was prepared by dispensing $95 \mu \mathrm{L}$ of SDA broth overlaid with $1 \mathrm{~mL}$ of olive oil and left for 15 minutes before adding $5 \mu \mathrm{L}$ of the yeast suspension into each well. One hundred $\mu \mathrm{L}$ from the stock solution of J. sambac essential oil at $100 \%$ concentration was added into the first well, then followed by $100 \mu \mathrm{L}$ of $75 \%$, $50 \%$, and $25 \%$ essential oil added to the next three wells consecutively. The plate was covered with a sterile plate shaker at $300 \mathrm{rpm}$ for 20 seconds and then incubated at $32^{\circ} \mathrm{C}$ for 48 hours. At the end of the incubation period, the plates were evaluated for the presence or absence of growth. MIC is the lowest concentration of the antifungal agent showing no turbidity after 48 hours, where the turbidity is interpreted as visible growth of the fungi. The bioassay was performed in triplicate in order to calculate the mean value.

\section{Results}

The skin samples obtained from the patients showed cell morphology bearing the hyphae that resembled the shape of spaghetti and meatball. The samples were tested positive for catalase due to the presence of gas bubbles in reaction to $10 \%$ hydrogen peroxide $\left(\mathrm{H}_{2} \mathrm{O}_{2}\right)$. Out of the five skin samples, 3 isolates were shown to be similar to the morphology of Malassezia sp. The isolates were named M1, M2, and M3, respectively, with $\mathrm{M} 1$ and $\mathrm{M} 2$ growing on SDA with olive oil and M3 without olive oil. The first isolate (M1) showed a creamy white and smooth colony, while the second (M2) isolate showed a creamy pink and smooth colony, both on SDA with olive oil. The third (M3) isolate showed a creamy white and smooth colony on SDA without olive oil. All isolates were then observed microscopically by Gram staining using a microscope. The morphology of cells according to isolates was presented in Figures 1-3. All isolates showed budding in the cells with M1 (Figure 1) and M2 (Figure 2) showing broad based budding while M3 (Figure 3) showing narrow based budding. Tween assimilation test indicated a positive growth on Tween 40, Tween 60, and Tween 80 for M1 (Figure 4) and positive growth on all the Tween 20, Tween 40, Tween 60, and Tween 80 for M2 isolate (Figure 5). M3 isolate, however, showed negative growth for all the Tween concentration as observed in Figure 6.

Table 1 showed the percentage yield of methanol extract and essential oil from both the leaves and flowers of the plant. The extraction yield using methanol showed that the flowers of J. sambac produced $20.69 \%$ crude extract whereas the yield from leaves of J. sambac was only $11.49 \%$. On the other hand, it was the leaves of the plant which produced a higher yield of essential oil (8.20\%) compared to its flowers, whereby only

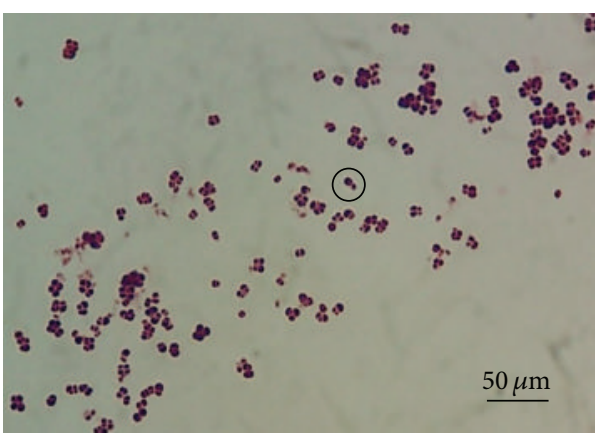

Figure 1: Cells from M1 isolate with broad based budding (Gram staining, magnification x1000).

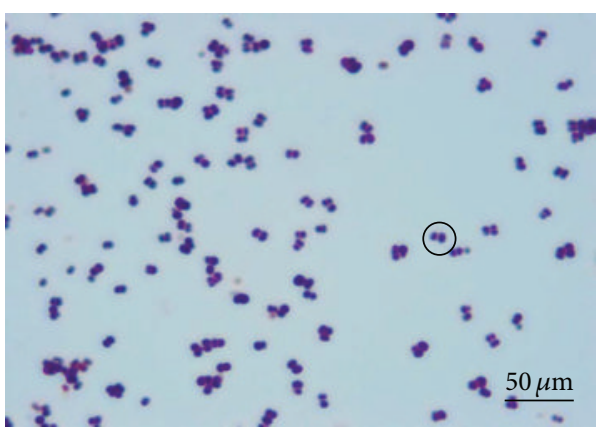

FIgURE 2: Cells from M2 isolate with broad based budding (Gram staining, magnification x1000).

$2.12 \%$ of the essential oil was obtained using hydrodistillation technique.

Table 2 showed the result of antifungal activity of the methanol extract from the leaves and flowers of J. sambac. All the isolates were susceptible towards the methanol extract from both parts of the plant with mean inhibition zone ranging from $9.10 \pm 1.92 \mathrm{~mm}$ to $12.90 \pm 1.68 \mathrm{~mm}$. M1 isolate showed the highest susceptibility towards the methanol extract from both the leaves and flowers with inhibitory zone of $11.10 \pm 1.92 \mathrm{~mm}$ and $12.90 \pm 1.68 \mathrm{~mm}$, whereas the methanol extract from J. sambac leaves and flowers exhibited the lowest inhibitory zone of $9.10 \pm 1.92 \mathrm{~mm}$ and $10.17 \pm 0.38 \mathrm{~mm}$, respectively against M3 isolate. Results of MIC value determination using microdilution assay showed that both the extracts from $J$. sambac have equal antifungal efficacy towards the M1 and M2 isolates with MIC values of the leaves extract and flower extract at, respectively, $160 \mathrm{mg} / \mathrm{mL}$ and $80 \mathrm{mg} / \mathrm{mL}$. This indicated that methanol extract of flowers exhibited twice inhibitory effect against Malassezia sp. compared to leaves. On the other hand, M3 isolate displayed weaker activity with MIC value of methanol extract from J. sambac leaves and flowers of $320 \mathrm{mg} / \mathrm{mL}$ and $160 \mathrm{mg} / \mathrm{mL}$, respectively.

Table 3 showed the result of antifungal activity of the essential oil from the leaves and flowers of J. sambac. Disc diffusion screening as measured by zone of inhibition showed that essential oil from J. sambac flowers produced mean inhibition zone ranging from $9.36 \pm 1.22 \mathrm{~mm}$ to $13.06 \pm 0.26 \mathrm{~mm}$. 


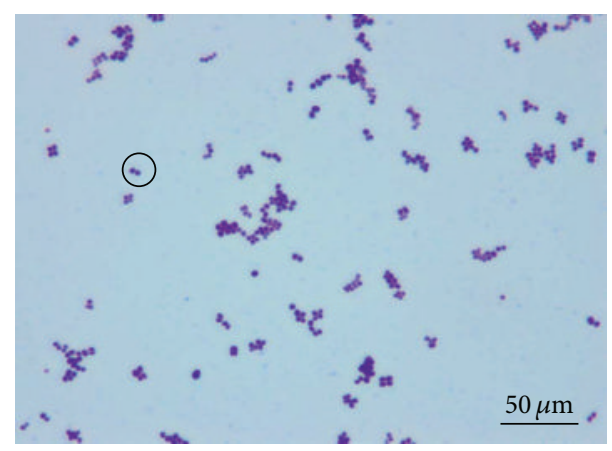

FIgURE 3: Cells from M3 isolate with narrow based budding (Gram staining, magnification x1000).

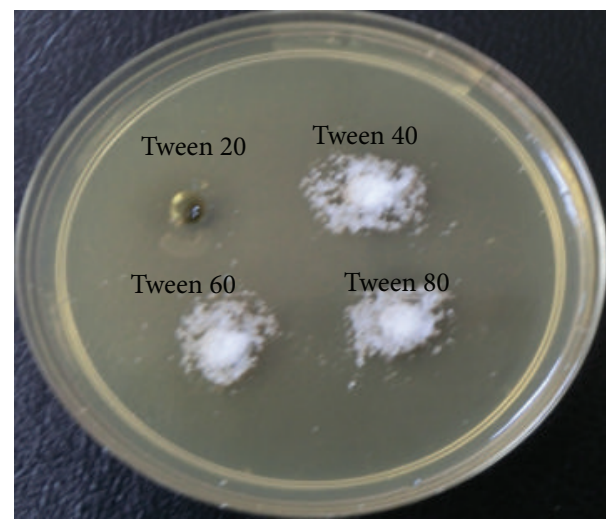

FIgURE 4: Tween assimilation of M1 isolate showing positive reaction towards Tween 40, Tween 60, and Tween 80 .

TABLE 1: Percentage yield of methanol extract and essential oil from the leaves and flowers of $J$. sambac.

\begin{tabular}{lcc}
\hline \multirow{2}{*}{ Parts of the plants } & \multicolumn{2}{c}{ Percentage yield (\%) } \\
& Methanol extract & Essential oil \\
\hline Leaves & 11.49 & 8.20 \\
Flowers & 20.69 & 2.12 \\
\hline
\end{tabular}

No antifungal activity was observed from the essential oil from the leaves of $J$. sambac as it did not produce any inhibitory effect against all isolates tested. The MIC values of essential oil from J. sambac flower against all isolates were in a range of $50 \%$ to $75 \%$ out of $100 \%$ in $100 \mu \mathrm{L}$ of essential oil. It was also clearly demonstrated that J. sambac flowers have the same antifungal efficacy towards both $\mathrm{M} 1$ and $\mathrm{M} 2$ isolates with MIC value of $50 \%$ strength of the essential oil.

\section{Discussion}

Although Malassezia is an opportunistic fungus in normal flora, it can be pathogenic and causes a variety of skin disorders which utilizes the lipid produced among humans due to the increasing population and global temperature [23]. Although these diseases were treatable with commercial antifungals, the need to continually use them over a long

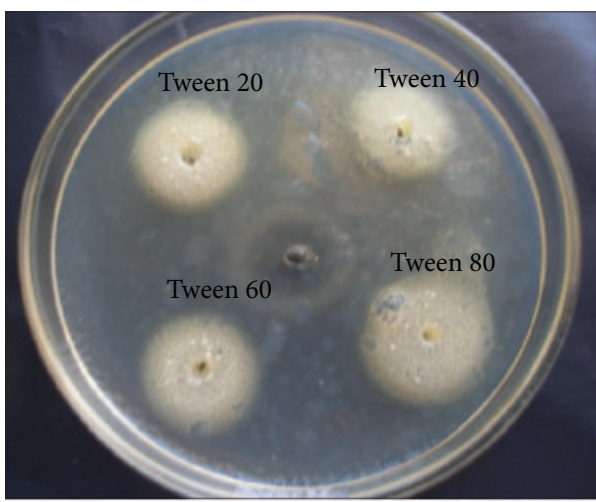

FIGURE 5: Tween assimilation of M2 isolate showing positive reaction towards Tween 20, Tween 40, Tween 60, and Tween 80 .

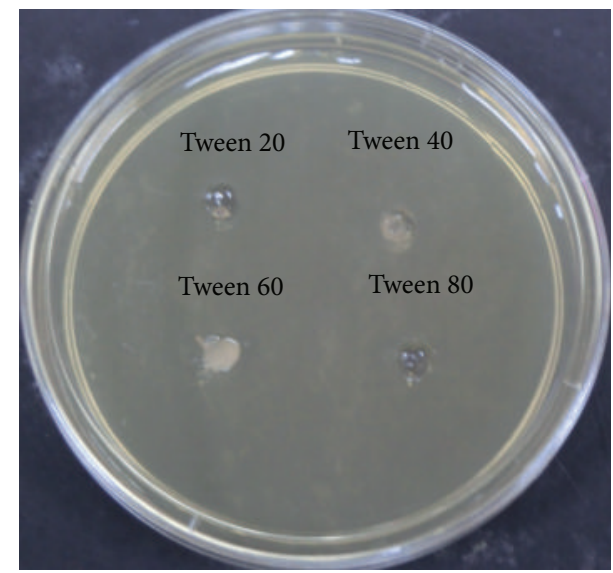

Figure 6: Tween assimilation of M3 isolate showing negative reaction towards Tween 20 , Tween 40 , Tween 60 , and Tween 80 .

period of time results in many side effects and can be the cause of increased resistance $[24,25]$.

The search for antimicrobial from natural sources has received much attention and effort has been put in to identify compounds that can act as suitable antimicrobial to replace synthetic agent. Natural plants have been used in many countries following remedies from tradition and custom due to its abundance and availability. Phytochemicals derived from plant product serve as a prototype to develop more effective medicine in controlling the growth of microorganism with less toxicity [26]. Throughout the history of mankind, many infectious diseases have been treated with plant extract. The extraction of extract from medicinal plant has shown that some of the screened plants are potentially rich source of antibacterial and antifungal agent $[27,28]$.

In the present study, the skin samples obtained from five subjects were cultured to isolate Malassezia sp. From the five samples, only three isolates of fungi were obtained which showed resemblance to Malassezia sp. Microscopical observation showed broad based budding of cells in M1 and M2 isolates whereas M3 showed narrow based budding. The broad based budding of M1 and M2 isolates mimicked the morphology of cells represented by Malassezia sp. [29]. 
TABLE 2: Antifungal activity of methanol extract from the leaves and flowers of $J$. sambac against M. sympodialis, M. dermatitis, or $M$. furfur and non-Malassezia species.

\begin{tabular}{|c|c|c|c|}
\hline Isolate & $\begin{array}{l}\text { Parts of the } \\
\text { plants }\end{array}$ & $\begin{array}{c}\text { Zone of } \\
\text { inhibition } \\
(\mathrm{mm} \pm \mathrm{SD})\end{array}$ & $\begin{array}{l}\text { MIC value } \\
(\mathrm{mg} / \mathrm{mL})\end{array}$ \\
\hline \multirow{3}{*}{ M1 } & Leaves & $11.10 \pm 1.92$ & 160 \\
\hline & Flowers & $12.90 \pm 1.68$ & 80 \\
\hline & $\begin{array}{l}\text { Positive } \\
\text { control }\end{array}$ & $15.67 \pm 1.68$ & 40 \\
\hline \multirow{3}{*}{ M2 } & Leaves & $10.87 \pm 1.28$ & 160 \\
\hline & Flowers & $11.17 \pm 0.38$ & 80 \\
\hline & $\begin{array}{c}\text { Positive } \\
\text { control }\end{array}$ & $16.67 \pm 1.11$ & 40 \\
\hline \multirow{3}{*}{ M3 } & Leaves & $9.10 \pm 1.92$ & 320 \\
\hline & Flowers & $10.17 \pm 0.38$ & 160 \\
\hline & $\begin{array}{l}\text { Positive } \\
\text { control }\end{array}$ & $15.88 \pm 1.68$ & 40 \\
\hline
\end{tabular}

Positive control used was Fluconazole at $40 \mathrm{mg} / \mathrm{mL}$. The diameter of inhibition zone was presented as a mean of 3 replicates. The isolates M1, M2, and M3 represented M. sympodialis, M. dermatitis, or M. furfur and nonMalassezia species, respectively.

TABle 3: Antifungal activity of essential oil from the leaves and flowers of J. sambac against $M$. sympodialis, $M$. dermatitis, or $M$. furfur and non-Malassezia species.

\begin{tabular}{lccc}
\hline Isolate & $\begin{array}{c}\text { Parts of the } \\
\text { plants }\end{array}$ & $\begin{array}{c}\text { Zone of } \\
\text { inhibition } \\
(\mathrm{mm} \pm \mathrm{SD})\end{array}$ & $\begin{array}{c}\text { MIC value } \\
(\%)\end{array}$ \\
\hline \multirow{3}{*}{ M1 } & Leaves & - & - \\
& $\begin{array}{c}\text { Flowers } \\
\text { Positive } \\
\text { control }\end{array}$ & $13.06 \pm 0.26$ & 50 \\
& Leaves & - & 25 \\
\hline \multirow{3}{*}{ M2 } & $\begin{array}{c}\text { Flowers } \\
\text { Positive }\end{array}$ & $12.36 \pm 1.33$ & - \\
& control & $15.87 \pm 1.72$ & 50 \\
\hline \multirow{2}{*}{ M3 } & Leaves & - & 25 \\
& $\begin{array}{c}\text { Flowers } \\
\text { Positive } \\
\text { control }\end{array}$ & $9.36 \pm 1.22$ & 75 \\
& $15.71 \pm 1.68$ & 25 \\
\hline
\end{tabular}

Positive control used was Fluconazole at $40 \mathrm{mg} / \mathrm{mL}$. The diameter of inhibition zone was presented as a mean of 3 replicates. - denotes no inhibition of bacterial growth. The isolates M1, M2, and M3 represented M. sympodialis, M. dermatitis, or M. furfur and non-Malassezia species, respectively.

All isolates were tested with Tween assimilation test which acts as a lipid provider for the fungus. M1 isolate showed positive growth towards Tween 40, Tween 60, and Tween 80 whereas positive growth was recorded by M2 isolate in all Tween. This indicated that M1 isolate could possibly be $M$. sympodialis while M2 isolate showed the possibility of either M. dermatitis or M. furfur species. M3 isolate showed negative growth towards all Tween and is therefore possibly M. globosa or a non-Malassezia species. However, since $M$. globosa needed lipid for its growth and isolation and M3 is isolated from SDA without olive oil, M3 can be confirmed as a non-Malassezia species. From these observations, M1 and M2 isolates were confirmed to be Malassezia sp. whereas M3 was identified as a non-Malassezia species.

The result of extraction yield of the J. sambac showed that methanol was capable of extracting the high quantity of constituents from the flowers of J. sambac whereas most of the essential oil was produced by the leaves of the plant. The high percentage yield of methanol extract indicated that methanol was the best solvent that can extract many of the polar active compounds found in the flowers compared to the leaves of $J$. sambac. The polarity of methanol and the solubility of plant secondary metabolites in methanol could be the probable reason for the high extractive value of methanol extract [30]. Hydrodistillation however produced higher yield of essential oil from the leaves of J. sambac compared to the flowers. This is supported by the finding that an essential oil is distilled from the fermented and dried leaves of Camellia sinensis, a source of the popular beverage tea [31].

Results obtained from the screening of antifungal activity indicated that the methanol extract from both the leaves and flowers of $J$. sambac showed inhibitory effect against all isolates tested. However, Malassezia sp. represented by M1 and M2 isolates appeared to be more susceptible towards the effect of $J$. sambac flowers which yield more phytocomponents extracted by methanol. The methanol flower extract showed higher yield and higher antifungal activity than the methanol leaves extract. Hence, it can be noted that as for methanol extraction the higher the extractive potential, the stronger the antifungal activity. However this is not the case for the hydrodistillation method because despite the high yield of essential oil from J. sambac leaves compared to its yield from the flowers, the former showed no inhibitory effect against all three isolates studied. This means that Malassezia sp. represented by M1 and M2 isolates was only susceptible to the essential oil from $J$. sambac flowers which might contain a promising antifungal phytoconstituent against Malassezia sp. The inability of essential oil of leaves to exhibit any inhibitory effect could mean that hydrodistillation method was unable to extract the active antifungal compound efficiently from the leaves of the plant [32]. In other words, this method of essential oil extraction is slightly ineffective if used on other parts of the plant other than the flowers. This is supported by [33] on multiple plants, which stated that hydrodistillation on other parts of a plant besides flowers produces less antimicrobial activity. However, there is no past research in order to make comparison that reports the antimicrobial potential of other parts of J. sambac besides flowers and therefore, this finding is interesting because it was shown that essential oil from other parts of J. sambac besides flowers cannot be exploited as a source of antimicrobial agent.

The presence of antifungal activity in the methanol extract from both the leaves and flowers of Jasminum sambac may be due to the presence of tannin. J. sambac flowers and leaves were reported to contain the polyphenol tannin and sambacin which are known to possess antimicrobial property [34]. However the essential oil from J. sambac flowers which comprise mainly $\alpha$-farnesene, benzyl acetate, 
and linalool [35] could contribute to its anti-Malassezia activity.

\section{Summary}

This study demonstrated that both the methanol and essential oil from the flowers of Jasminum sambac showed promising inhibitory effect against Malassezia sp. isolated from the skin samples of patients with dandruff. In conclusion, $J$. sambac flowers can be developed as potential phytotherapeutic source of treatment against Malassezia-associated skin infections and possibly as an additive ingredient in the development of medicated shampoo against dandruff as well as skin and scalp infections.

\section{Recommendation}

However, further investigation to evaluate the antifungal activity of $J$. sambac in mice infected with Malassezia sp. is necessary to correlate the effectiveness of its methanol extract and essential flowers in vivo.

\section{Conflict of Interests}

The authors declare that there is no conflict of interests regarding the publication of this paper.

\section{Acknowledgment}

This research was funded by the Ministry of Higher Education, Government of Malaysia, under the research Grant code FRGS/1/2012/SG06/UKM/02/7.

\section{References}

[1] A. K. Gupta, R. Batra, R. Bluhm, T. Boekhout, and T. L. Dawson Jr., "Skin diseases associated with Malassezia species," Journal of the American Academy of Dermatology, vol. 51, no. 5, pp. 785798, 2004.

[2] T. L. Cheng, S. M. Rovito, D. B. Wake, and V. T. Vredenburg, "Coincident mass extirpation of neotropical amphibians with the emergence of the infectious fungal pathogen Batrachochytrium dendrobatidis," Proceedings of the National Academy of Sciences of the United States of America, vol. 108, no. 23, pp. 9502-9507, 2011.

[3] A. B. Thayikkannu, A. J. Kindo, and M. Veeraragahavan, "Characterisation of Malassezia species and their clinical correlation in a tertiary healthcare centre in South India," Journal of the Academy of Clinical Microbiologists, vol. 15, no. 2, pp. 49-53, 2013.

[4] M. David, M. Gabriel, and M. Kopecká, "Unusual ultrastructural characteristics of the yeast Malassezia pachydermatis," Scripta Medica (Brno), vol. 76, no. 3, pp. 173-186, 2003.

[5] C. A. Akdis, M. Akdis, T. Bieber et al., "Diagnosis and treatment of atopic dermatitis in children and adults: European Academy of Allergology and Clinical Immunology/American Academy of Allergy, Asthma and Immunology/PRACTALL Consensus Report," Journal of Allergy and Clinical Immunology, vol. 118, no. 1, pp. 152-169, 2006.
[6] R. Kaur, R. Goyal, M. S. Dhakad, P. Bhalla, and R. Kumar, "Epidemiology and virulence determinants including biofilm profile of Candida infections in an ICU in a tertiary hospital in India," Journal of Mycology, vol. 2014, Article ID 303491, 8 pages, 2014.

[7] I. Kubo, H. Muroi, and A. Kubo, "Naturally occurring antiacne agents," Journal of Natural Products, vol. 57, no. 1, pp. 9-17, 1994.

[8] A. Mittal, S. Sardana, and A. Pandey, "Ethnobotanical, phytochemical and pharmacological profile of Jasminum sambac (L) Ait," Journal of Pharmaceutical and Biomedical Sciences, vol. 11, no. 5, pp. 30-35, 2011.

[9] J. Xu, C. W. Saunders, P. Hu et al., "Dandruff-associated Malassezia genomes reveal convergent and divergent virulence traits shared with plant and human fungal pathogens," Proceedings of the National Academy of Sciences of the United States of America, vol. 104, no. 47, pp. 18730-18735, 2007.

[10] R. Nair and S. Chanda, "Activity of some medicinal plants against certain pathogenic bacterial strains," Indian Journal of Pharmacology, vol. 38, no. 2, pp. 142-144, 2006.

[11] F. Abdoul-Latif, P. Edou, F. Eba et al., "Antimicrobial and antioxidant activities of essential oil and methanol extract of Jasminum sambac from Djibouti," African Journal of Plant Science, vol. 4, no. 3, pp. 38-43, 2010.

[12] R. Aho, "Saprophytic fungi isolated from the hair of domestic and laboratory animals with suspected dermatophytosis," Mycopathologia, vol. 83, no. 2, pp. 65-73, 1983.

[13] A. Ali, "Diseases of the skin: a color atlas and text," Archives of Dermatology, vol. 139, no. 6, p. 819, 2003.

[14] S. Luangnarumitchai, S. Lamlertthon, and W. Tiyaboonchai, "Antimicrobial activity of essential oils against five strains of Propionibacterium acne," Mahidol University Journal of Pharmaceutical Sciences, vol. 34, no. 1-4, pp. 60-64, 2007.

[15] P. Joy and P. Raja, "Antibacterial activity studies of Jasminum grandiflorum and Jasminum sambac," Ethnobotanical Leaflets, vol. 12, pp. 481-483, 2008.

[16] M. M. Cowan, "Plant products as antimicrobial agents," Clinical Microbiology Reviews, vol. 12, no. 4, pp. 564-582, 1999.

[17] J. K. Holopainen, "Multiple functions of inducible plant volatiles," Trends in Plant Science, vol. 9, no. 11, pp. 529-533, 2004.

[18] V. P. Kumar, N. S. Chauhan, H. Padh, and M. Rajani, "Search for antibacterial and antifungal agents from selected Indian medicinal plants," Journal of Ethnopharmacology, vol. 107, no. 2, pp. 182-188, 2006.

[19] J. M. Karhoot, A. A. Noaimi, and W. F. Ahmad, "Isolation and identification of Malassezia species in patients with pityriasis versicolor," The Iraqi Postgraduate Medical Journal, vol. 11, no. 6, pp. 724-730, 2012.

[20] A. Velegraki, E. C. Alexopoulos, S. Kritikou, and G. Gaitanis, "Use of fatty acid RPMI 1640 media for testing susceptibilities of eight Malassezia species to the new triazole posaconazole and to six established antifungal agents by a modified NCCLS M27-A2 microdilution method and Etest," Journal of Clinical Microbiology, vol. 42, no. 8, pp. 3589-3593, 2004.

[21] P. R. Murray, E. J. Baron, C. D. Pfaller, F. C. Tenover, and R. H. Yolke, Manual of Clinical Microbiology, ASM, Washington, DC, USA, 6th edition, 1995.

[22] A. W. Bauer, W. M. Kirby, J. C. Sherris, and M. Turck, "Antibiotic susceptibility testing by a standardized single disk method," American Journal of Clinical Pathology, vol. 45, no. 4, pp. 493496, 1966. 
[23] C. W. Saunders, A. Scheynius, and J. Heitman, "Malassezia fungi are specialized to live on skin and associated with dandruff, eczema, and other skin diseases," PLoS Pathogens, vol. 8, no. 6, Article ID e1002701, 2012.

[24] T. Koyama, T. Kanbe, A. Kikuchi, and Y. Tomita, "Effects of topical vehicles on growth of the lipophilic Malassezia species," Journal of Dermatological Science, vol. 29, no. 3, pp. 166-170, 2002.

[25] K. A. Hammer, C. F. Carson, and T. V. Riley, "In vitro activities of ketoconazole, econazole, miconazole, and Melaleuca alternifolia (tea tree) oil against Malassezia species," Antimicrobial Agents and Chemotherapy, vol. 44, no. 2, pp. 467-469, 2000.

[26] D. Bhowmik, D. P. Chatterjee, A. Mallik, and A. Roy, "Study of the analgesic activity of methanolic extract of jasmine root (Jasminum sambac)," Indian Journal of Research in Pharmacy and Biotechnology, vol. 1, pp. 14-16, 2005.

[27] R. Al-Hussaini, M. Adel, and M. Mahasneh, "Microbial growth and quorum sensing antagonist activities of herbal plants extracts," Journal of Chromatography A, vol. 1043, pp. 323-327, 2004.

[28] G. G. F. Nascimento, J. Locatelli, P. C. Freitas, and G. L. Silva, "Antibacterial activity of plant extracts and phytochemicals on antibiotic-resistant bacteria," Brazilian Journal of Microbiology, vol. 31, no. 4, pp. 247-256, 2000.

[29] C. Cafarchia, D. Otranto, B. E. Campbell, M. S. Latrofa, J. Guillot, and R. B. Gasser, "Multilocus mutation scanning for the analysis of genetic variation within Malassezia (Basidiomycota: Malasseziales)," Electrophoresis, vol. 28, no. 8, pp. 1176-1180, 2007.

[30] D. F. Basri, N. Saidi, H. Mahari, S. Saari, and J. Santhanam, "Preliminary screening for antimicrobial activity of the pulp of Canarium odontophyllum Miq. (Dabai) fruit," Global Journal of Pharmacology, vol. 8, no. 2, pp. 213-220, 2014.

[31] D. Bown, Encyclopedia of Herbs \& Their Uses, Dorling Kindersley Publishers, London, UK, 1st edition, 1995.

[32] C. Rath, S. Devi, S. Dash, and R. Mishra, "Antibacterial potential assessment of Jasmine essential oil against E. coli," Indian Journal of Pharmaceutical Sciences, vol. 70, no. 2, pp. 238-241, 2008.

[33] G. Harisingh, "Essential oils as theraupeutics," Natural Product Radiance, vol. 4, no. 1, pp. 18-26, 2005.

[34] A. Jain, R. Sharma, A. Kumar, and S. Sharma, "Jasminum species: an overview," International Journal of Institutional Pharmacy and Life Sciences, vol. 1, no. 1, pp. 251-266, 2011.

[35] R. Kaiser, "New volatile constituents of Jasminum sambac (L.) Aiton," in Proceedings of the 10th International Congress on Essential Oils, B. M. Lawrence, B. D. Mookherjee, and B. J. Willis, Eds., Flavors and Fragrances: A World Perspective, pp. 669-684, Elsevier Science, Armsterdam, the Netherlands, 1988. 

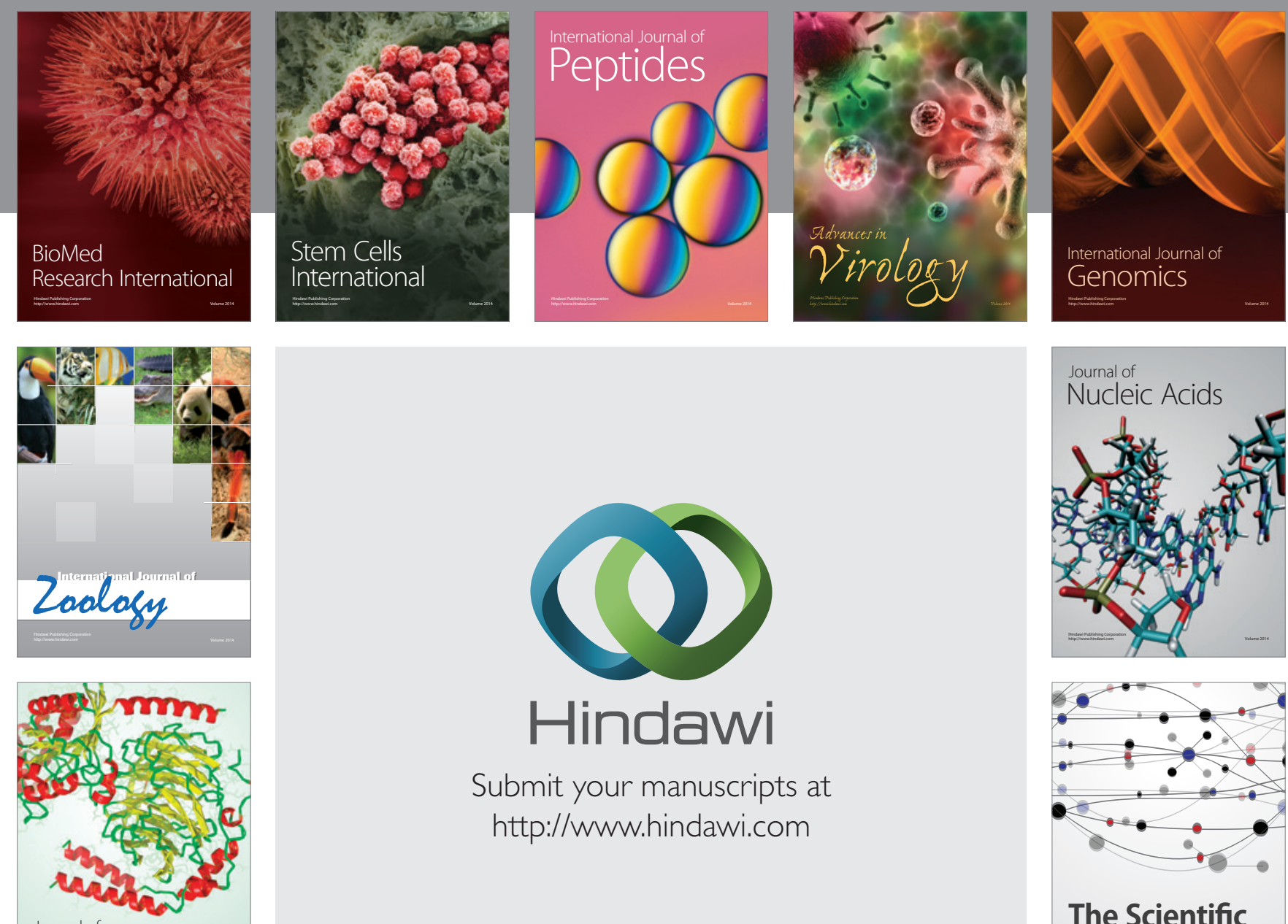

Submit your manuscripts at

http://www.hindawi.com

Journal of
Signal Transduction
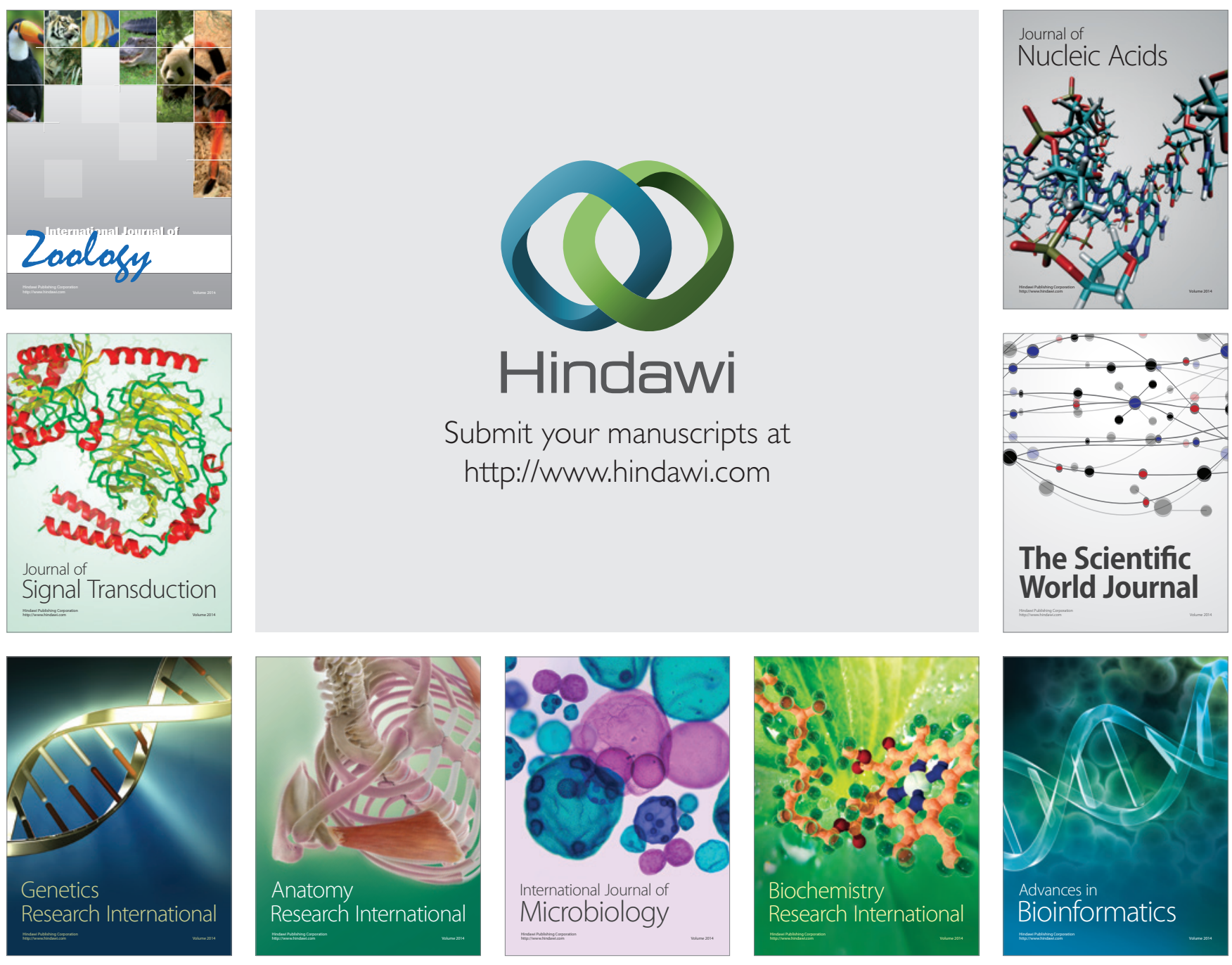

The Scientific World Journal
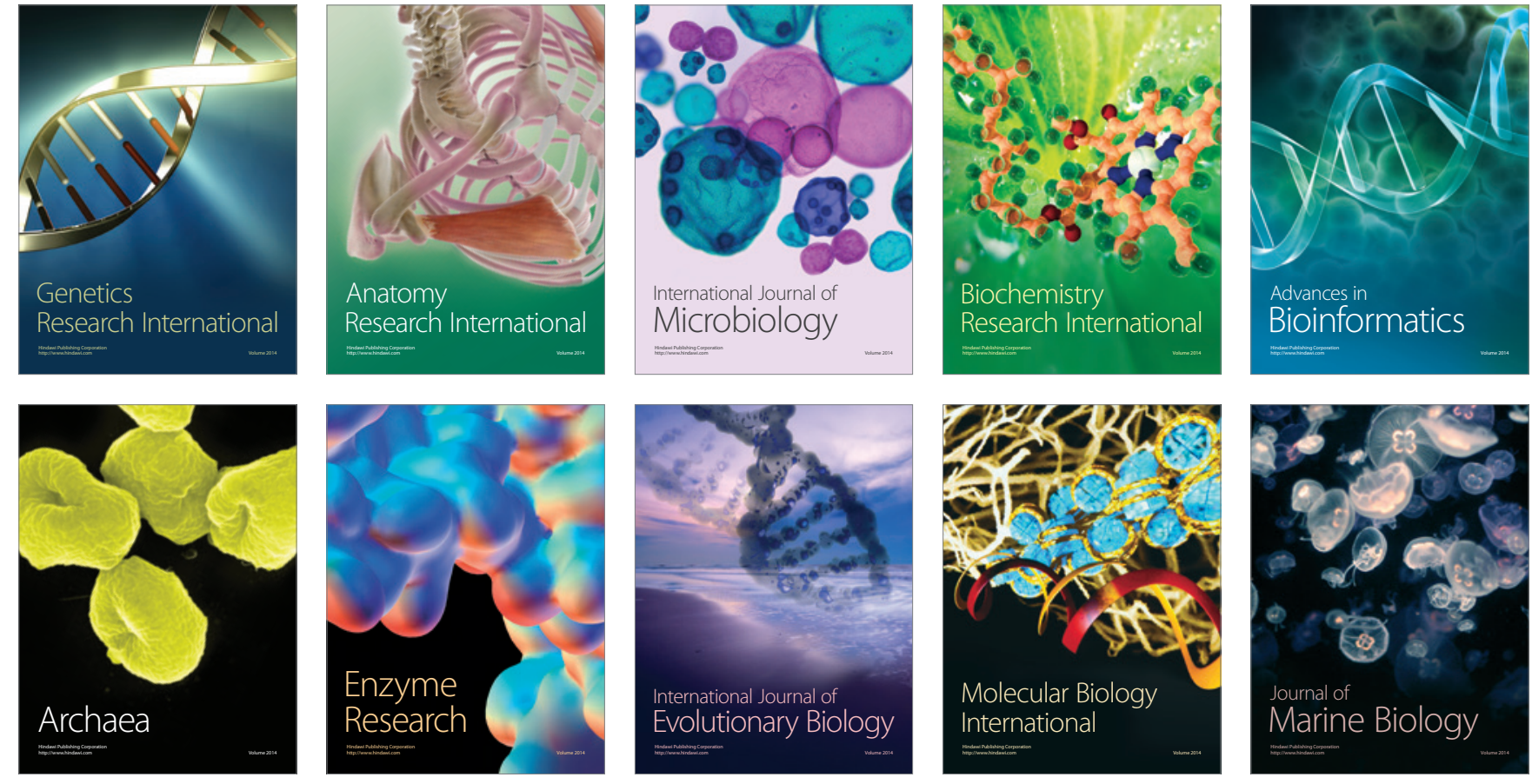